\title{
Low HbA1c With Normal Hemoglobin in a Diabetes Patient Caused by PIEZ01 Gene Variant: A Case Report
}

\author{
An Song ${ }^{1}$, Lin Lu ${ }^{1 *}$, Yuxiu Li ${ }^{1}$, Mei Lin ${ }^{2}$, Xingxing Yuan ${ }^{3}$, Xinqi Cheng ${ }^{3}$, Weibo Xia ${ }^{1}$, \\ Ou Wang ${ }^{1}$ and Xiaoping Xing ${ }^{1}$
}

${ }^{1}$ Key Laboratory of Endocrinology of National Health Commission, Department of Endocrinology, Peking Union Medical College Hospital, Chinese Academy of Medical Science and Peking Union Medical College, Beijing, China, ${ }^{2}$ Department of Internal Medicine, Peking Union Medical College Hospital, Peking Union Medical College, Chinese Academy of Medical Sciences, Beijing, China, ${ }^{3}$ Department of Laboratory, Peking Union Medical College Hospital, Peking Union Medical College, Chinese Academy of Medical Sciences, Beijing, China

Background: Diabetes is a global disease with rapidly increasing prevalence in the world. Glycated hemoglobin ( $\mathrm{HbA} 1 \mathrm{c})$ as an important indicator of diabetes could reflect the average serum glucose level over 120 days. However, when using $\mathrm{HbA} 1 \mathrm{c}$ to diagnose diabetes, it is important to consider other factors that may impact $\mathrm{HbA1c}$ level including age, race/ethnicity, detection method, and co-morbidities. Here we report a case of diabetes with normal hemoglobin but reduced $\mathrm{HbA} 1 \mathrm{c}$.

OPEN ACCESS

Edited by:

Anca Dana Dobrian, Eastern Virginia Medical School,

United States

Reviewed by:

Yoshifumi Saisho,

Keio University, Japan

Roberta Russo,

University of Naples Federico II, Italy

*Correspondence:

Lin Lu

Iulin88@sina.com

Specialty section:

This article was submitted to

Clinical Diabetes,

a section of the journal

Frontiers in Endocrinology

Received: 25 November 2019

Accepted: 06 May 2020

Published: 19 June 2020

Citation:

Song A, Lu L, Li Y, Lin M, Yuan X, Cheng $X$, Xia $W$, Wang $O$ and Xing $X$ (2020) Low HbA1c With Normal

Hemoglobin in a Diabetes Patient Caused by PIEZO1 Gene Variant: A Case Report.

Front. Endocrinol. 11:356. doi: 10.3389/fendo.2020.00356
Case report: A 57-year-old female patient was diagnosed with diabetes by oral glucose tolerance test results. However, the HbA1c level was repeatedly decreased, glycated albumin level was high, with normal levels of hemoglobin and albumin, and a slightly elevated level of bilirubin. Moreover, life span of red blood cells was significantly shortened. Further examination of whole exome sequencing of the patient and her daughter showed heterozygous variant in PIEZO1 gene (c.6017T > A) in both, which is associated with dehydration hereditary stomatocytosis (DHS). After this diagnosis, we changed nateglinide to sitagliptin to reduce the burden of the pancreas islet function.

Conclusion: In case of abnormally low $\mathrm{HbA} 1 \mathrm{c}$, we recommend that GA and reticulocyte should be measured simultaneously. Moreover, the methodology for hemoglobin measurement and the diseases that could cause abnormal quantity and quality of red blood cells and hemoglobin be considered.

Keywords: diabetes, glycated hemoglobin, glycated albumin, hemolytic anemia, PIEZO1 gene

\section{INTRODUCTION}

Diabetes is a global disease with rapidly increasing prevalence in the world. The American Diabetes Association has recommended glycated hemoglobin (HbAlc) as an important indicator of diabetes and a useful monitoring tool for long-term glycemic control (1). The reference range of $\mathrm{HbAlc}$ derived from DCCT/UKPDS is $4-6 \%$. Since the life span of red blood cells in circulation is 120 days, HbA1c percentage reflects the average serum glucose level over 120 days, with biological variation $<2 \%$ (2). However, when using HbAlc to diagnose diabetes, it is important to consider other factors that may impact HbAlc level including age, race/ethnicity, detection method, and co-morbidities (1). While diabetes is indicated by high levels of $\mathrm{HbAlc}$, there are also probable causes that are indicated by abnormally low HbAlc levels $(<4 \%)$. The possible causes include laboratory error, extreme diet control, excessive use of 
antidiabetic drugs, and anemia/hemoglobinopathies (3). Here we report a case of diabetes with normal hemoglobin but reduced HbA1c. Hemolytic diseases with normal hemoglobin are not uncommon. However, their influence on the determination of glycosylated hemoglobin is still poorly understood.

\section{CASE PRESENTATION}

In 2010, a 57-year-old female patient presented with mild polydipsia, polyuria, blurred vision, and weight loss. Diabetes mellitus was diagnosed by oral glucose tolerance test results (OGTT, determination of glucose and insulin at 0 and $120 \mathrm{~min}$ ). The HbA1c level at that time was 3.6\% and glycated albumin (GA) was 16.3\% (normal range: 10.8-17.1\%). Type 1 diabetes-associated antibodies such as Islet Cell Antibodies (ICA), Glutamic Acid Decarboxylase antibodies (GAD), Insulin Autoantibodies (IAA), and insulinoma-antigen 2 (IA2A) were all negative. Total bilirubin (TBil) was $38.7 \mathrm{umol} / \mathrm{L}$ (normal range: 5.1-22.2) and direct bilirubin (DBil) was $11.6 \mathrm{umol} / \mathrm{L}$ (normal range: 0-6.8). Other laboratory tests including serum alanine transaminase (ALT), albumin, and renal function test were all within the normal range. Upon diagnosing her with diabetes mellitus, the primary doctor prescribed nateglinide to control the hyperglycemia. In recent years, her $\mathrm{HbA} 1 \mathrm{c}$ level were found repeatedly reduced, while the level of GA remained high. Hemoglobin (Hgb) and albumin were still in the normal range, and the bilirubin level was found slightly elevated. In terms of screening for diabetic complications, the patient had completed the fundus examination, renal ultrasound, cardiac ultrasound, lower limb artery ultrasound, $24 \mathrm{~h}$ urine protein, and urine albumin-to-creatinine ratio, and no abnormalities were found. However, the carotid ultrasound showed the presence of atherosclerotic plaques. Past medical history showed the patient suffered from keratoconjunctivitis sicca for 10 years and carotid atherosclerosis for 3 years. The family history showed her mother also suffered from diabetes mellitus with similarly low HbAlc level (3.4\%) and slightly decreased Hgb (102 G/L). Her mother also had Sjogren syndrome and passed away at age of 70 years old without further investigation of the causes of low HbAlc. In addition, both her mother and daughter had hyperbilirubinemia. The complete blood count of the daughter showed that normal $\mathrm{Hgb}(156 \mathrm{G} / \mathrm{L})$ and increased reticulocyte $\left(169.9 \times 10^{9} / \mathrm{L}\right.$, normal range: $\left.24.0-84.0 \times 10^{9} / \mathrm{L}\right)$, normal white blood cell $\left(6.55 \times 10^{9} / \mathrm{L}\right)$ and Platelet $\left(321 \times 10^{9} / \mathrm{L}\right)$.

After recent hospitalization in our medical center, the abnormally low HbAlc levels attracted our attention. To confirm the problem, we performed repeated HbAlc test by both ionexchange chromatography and immunization method. However, the low HbAlc level persisted. Hemoglobin electrophoresis revealed no abnormality. After excluding laboratory error and variation of hemoglobin, we performed further laboratory examinations (Table 1): Hgb was $129 \mathrm{G} / \mathrm{L}$, reticulocyte was $265.4 \times 10^{9} / \mathrm{L}$ (normal range: $24.0-84.0 \times 10^{9} / \mathrm{L}$ ), TBil was $29 \mathrm{umol} / \mathrm{L}$, DBil was $7.6 \mathrm{umol} / \mathrm{L}$, and the life span of red blood cells measured by $\mathrm{CO}$ breath test was significantly shortened to 43 days (normal range: $>75$ days). All these
TABLE 1 | Clinical features and laboratory results of this patient.

\begin{tabular}{|c|c|c|c|c|c|}
\hline & & \multicolumn{2}{|c|}{$\begin{array}{l}\text { Clinical features and } \\
\text { laboratory findings }\end{array}$} & \multicolumn{2}{|c|}{ Reference range } \\
\hline Age (year) & \multicolumn{3}{|c|}{57} & & \\
\hline Weight (kg) & \multicolumn{3}{|c|}{50} & & \\
\hline Height (cm) & \multicolumn{3}{|c|}{159} & & \\
\hline $\mathrm{BMl}\left(\mathrm{kg} / \mathrm{m}^{2}\right)$ & \multicolumn{3}{|c|}{19.78} & & \\
\hline HbA1c (\%) & \multicolumn{3}{|c|}{3.4} & \multicolumn{2}{|c|}{$4.5-6.3$} \\
\hline GA (\%) & \multicolumn{3}{|c|}{14.5} & \multicolumn{2}{|c|}{$10.8-17.1$} \\
\hline $\mathrm{Hgb}(\mathrm{g} / \mathrm{L})$ & \multicolumn{3}{|c|}{129} & \multicolumn{2}{|c|}{$120-160$} \\
\hline Free hemoglobin & \multicolumn{3}{|c|}{2.3} & \multicolumn{2}{|c|}{$0-5$} \\
\hline Reticulocyte $(\times 10$ & \multicolumn{3}{|c|}{265.40} & \multicolumn{2}{|c|}{$24.0-84.0$} \\
\hline Reticulocyte (\%) & \multicolumn{3}{|c|}{7.49} & \multicolumn{2}{|c|}{$0.8-2$} \\
\hline MCV (fl) & \multicolumn{3}{|c|}{102.8} & \multicolumn{2}{|c|}{ 82.0-97.0 } \\
\hline $\mathrm{MCH}(\mathrm{pg})$ & \multicolumn{3}{|c|}{36.6} & \multicolumn{2}{|c|}{$27.0-32.0$} \\
\hline $\mathrm{MCHC}(\mathrm{g} / \mathrm{L})$ & \multicolumn{3}{|c|}{356} & \multicolumn{2}{|c|}{$320-360$} \\
\hline RDW (\%) & \multicolumn{3}{|c|}{14.6} & \multicolumn{2}{|c|}{$0.0-15.0$} \\
\hline Hematocrit (\%) & \multicolumn{3}{|c|}{36.4} & \multicolumn{2}{|c|}{$35.0-50.0$} \\
\hline Platelet $\left(\times 10^{9} / \mathrm{L}\right)$ & \multicolumn{3}{|c|}{191} & \multicolumn{2}{|c|}{$100-350$} \\
\hline WBC $\left(\times 10^{9} / L\right)$ & & & & & \\
\hline Iron ( $\mu \mathrm{g} / \mathrm{dl})$ & & & & & \\
\hline Ferritin (ng/ml) & & & & & \\
\hline TIBC $(\mu \mathrm{g} / \mathrm{dl})$ & & & & & 50 \\
\hline TS (\%) & & & & & 0.0 \\
\hline $\mathrm{ALT}(\mathrm{U} / \mathrm{L})$ & & & & & \\
\hline ALB(g/L) & & & & & \\
\hline TBIL( $\mu \mathrm{mol} / \mathrm{L})$ & & & & & 2.2 \\
\hline $\mathrm{DBIL}(\mu \mathrm{mol} / \mathrm{L})$ & & & & & \\
\hline $\mathrm{LDH}(\mathrm{U} / \mathrm{L})$ & & & & & \\
\hline $\mathrm{K}(\mathrm{mmol} / \mathrm{L})$ & & & & & \\
\hline OGTT & $\mathbf{O h}$ & $0.5 \mathrm{~h}$ & $1 \mathrm{~h}$ & $2 \mathrm{~h}$ & $3 \mathrm{~h}$ \\
\hline GLU (mmol/L) & 5.5 & 8.0 & 13.1 & 13.1 & 10.6 \\
\hline INS ( $\mu \mathrm{IU} / \mathrm{mL})$ & 4.51 & 17.66 & 40.88 & 41.77 & 41.65 \\
\hline C-P (ng/mL) & 0.93 & 1.83 & 3.51 & 5.65 & 6.15 \\
\hline
\end{tabular}

BMI, body mass index; underweight $\leq 18.5$, normal weight $=18.5-24.9$, overweight = 25-29.9, obesity $=$ BMl of 30 or greater; HbA1C, glycated hemoglobin; GA, glycated albumin; Hgb, hemoglobin; MCV, mean corpuscular volume; $\mathrm{MCH}$, mean corpuscular hemoglobin; MCHC, mean corpuscular hemoglobin concentration; RDW, red cell distribution width; WBC, white blood cell; TIBC, total iron binding capacity; TS, transferrin saturation; $A L T$, alanine transaminase; $A L B$, albumin; $T B I L$, total bilirubin; $D B I L$, direct bilirubin; $L D H$, lactate dehydrogenase; $K$, serum potassium; OGTT, oral glucose tolerance test; GLU, glucose; INS, insulin; C-P, C-Peptide.

results above indicated the presence of hemolytic anemia. However, screening for common causes (erythrocyte osmotic fragility, 6-phosphate glucose dehydrogenase test and plasma free hemoglobin test, Ham test, Rous test, and Coombs test were all in normal range) of acquired hemolytic disease led to exclusion of autoimmune hemolysis, glucose-6-phosphate dehydrogenase deficiency, paroxysmal hemoglobinuria, and so on. Pancreatic MRI showed slightly atrophied pancreatic body, but iron deposition in the pancreas was normal $(23.7 \mathrm{~ms}$ at T2 $*)$. Both the patient and her daughter showed heterozygous variant in PIEZO1 gene (c.6017T > A, p.V2006D) by whole exome sequencing of the blood with confirmation of sanger sequencing (Figure 1), which 


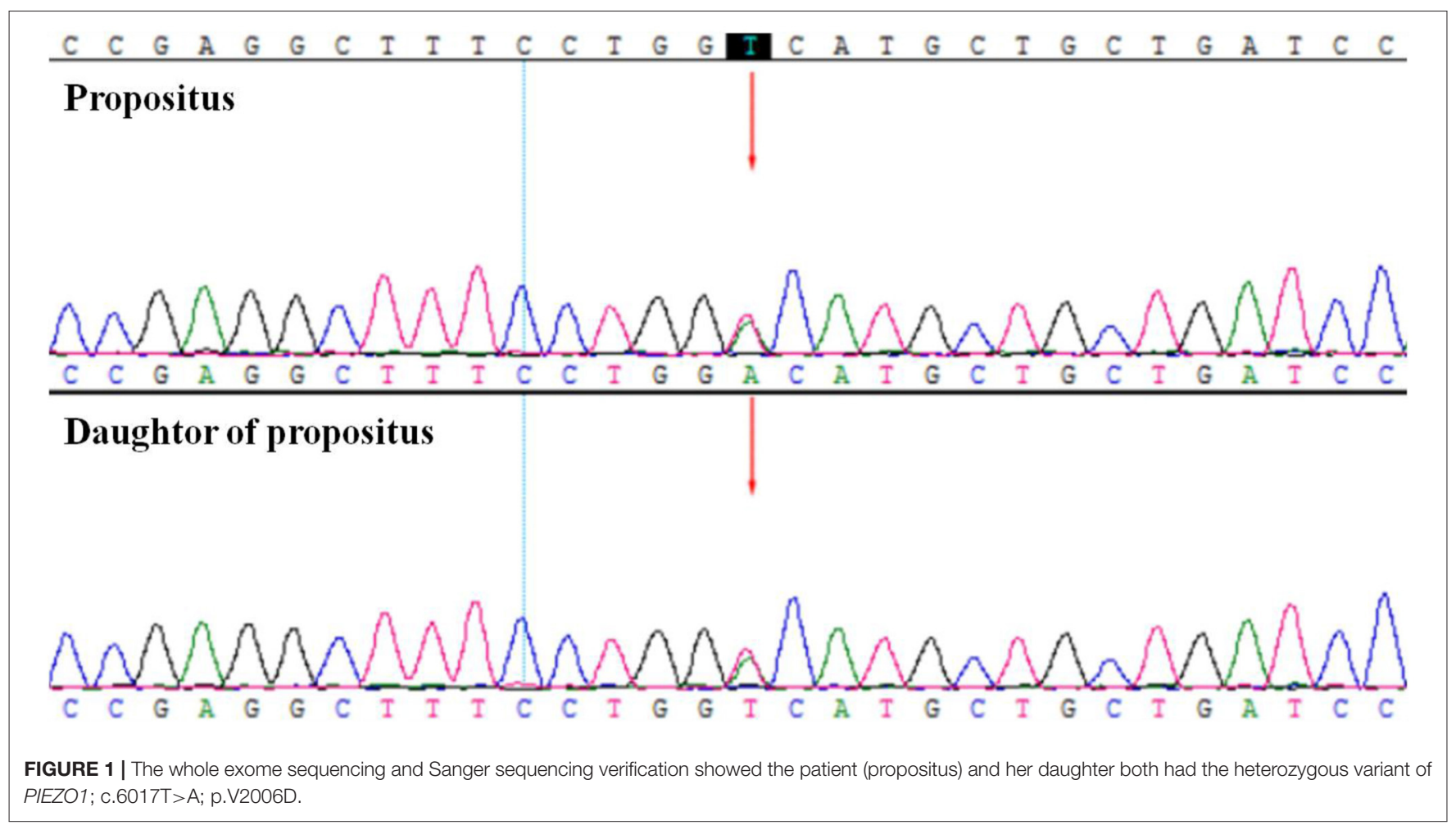

is associated with dehydration hereditary stomatocytosis (DHS). After this diagnosis, nateglinide was changed to sitagliptin to reduce the burden of the pancrea islet function.

\section{DISCUSSION}

In the absence of other confounding factors, HbAlc correlates with mean blood glucose (MBG) and GA to some extent. There were some studies about the correlation of $\mathrm{HbA1c}$ with MBG. In a study by Nathan et al., a total of 268 patients with type 1 diabetes, 159 patients with type 2 diabetes, and 80 non-diabetic subjects were enrolled (4). Continuous glucose monitoring (CGM) and self-monitoring of blood glucose (SMBG) were recorded for 3 months and was used to calculate their MBG. For total participants, $\mathrm{MBG}=1.59 \times \mathrm{HbAlc}-2.59$, while for the diabetes patients, $\mathrm{MBG}=1.57 \times \mathrm{HbAlc}-2.44\left(R^{2}=0.79, P<0.01\right)$. The corresponding relationship between HbAlc and MBG obtained from this study is given in 2019 standards of medical care in diabetes by the American Diabetes Association (ADA) (Table 2) (1). However, the limitation of this study was that it mostly incorporated non-Hispanic whites, and therefore may not have been reflective of findings in the general population. In a similar study by $\mathrm{Ma}$ et al., from 2007 to 2010,318 patients were investigated, including 115 cases of the normal control group, 57 cases of impaired glucose regulation group, and 146 cases of newly diagnosed type 2 diabetes mellitus group. This study primarily investigated the relationship between MBG and HbAlc in the Chinese population (Table 2) (5). For the total participants, $\mathrm{MBG}=1.252 \times$ HbAlc-0.992 $\left(R^{2}=0.718, P<0.01\right)$; for newly diagnosed T2DM patients, $\mathrm{MBG}=1.255 \times$ HbAlc- 0.886
TABLE 2 | Mean glucose levels for specified HbA1c and GA levels.

\begin{tabular}{|c|c|c|c|}
\hline \multirow[t]{2}{*}{ HbA1c (\%) } & \multirow{2}{*}{$\begin{array}{c}\text { Non-Hispanic whites (1) } \\
\text { MBG } \\
(\mathrm{mmol} / \mathrm{l}, 95 \% \mathrm{Cl})\end{array}$} & \multicolumn{2}{|c|}{ Chinese population $(5,6)$} \\
\hline & & $\begin{array}{c}\text { MBG } \\
(\mathrm{mmol} / \mathrm{l}, 95 \% \mathrm{Cl})\end{array}$ & $\begin{array}{c}\text { GA } \\
(\%, 95 \% \mathrm{Cl})\end{array}$ \\
\hline 5.0 & & $5.3(4.3-6.3)$ & $14.2(12.9-15.5)$ \\
\hline 5.5 & & $5.9(4.8-7.0)$ & - \\
\hline 6.0 & $7.0(5.5-8.5)$ & $6.5(5.4-7.6)$ & $17.1(15.7-18.5)$ \\
\hline 6.5 & & $7.1(6.0-8.3)$ & $19.6(17.0-22.1)$ \\
\hline 7.0 & $8.6(6.8-10.3)$ & $7.8(6.6-9.0)$ & $20.0(18.5-21.5)$ \\
\hline 7.5 & & $8.4(7.2-9.6)$ & $21.4(19.8-23.0)$ \\
\hline 8.0 & $10.2(8.1-12.1)$ & $9.0(7.7-10.3)$ & $22.9(21.2-24.5)$ \\
\hline 8.5 & & $9.7(8.3-11.0)$ & - \\
\hline 9.0 & $11.8(9.4-13.9)$ & $10.3(8.9-11.6)$ & $25.7(24.0-27.5)$ \\
\hline 9.5 & & $10.9(9.5-12.3)$ & - \\
\hline 10.0 & $13.4(10.7-15.7)$ & $11.5(10.1-13.0)$ & $28.6(26.7-30.5)$ \\
\hline 10.5 & & $12.2(10.7-13.7)$ & - \\
\hline 11 & $14.9(12.0-17.5)$ & $12.8(11.2-14.3)$ & $31.5(29.5-33.5)$ \\
\hline 12 & $16.5(13.3-19.3)$ & $14.0(12.4-15.7)$ & $34.3(32.2-36.4)$ \\
\hline
\end{tabular}

HbA1c, Glycated hemoglobin; MBG, Mean blood glucose: GA, Glycated albumin.

$\left(R^{2}=0.621, P<0.01\right)$. These studies demonstrated that the relationships between $\mathrm{HbAlc}$ and $\mathrm{MBG}$ hold irrespective of the demographics being studied, and therefore this finding has clinical significance.

For the correlation between HbA1c and GA, in another study, Ma et al. collected the HbA1c and GA level of 2,532 patients (898 in the normal control group, 695 in impaired glucose regulation group, and 939 in newly diagnosed T2DM group), and found 
that there was a significant positive correlation $(R=0.701, P$ $<0.01)$ between the two factors (6). The regression equation obtained was $\mathrm{GA}=2.871 \times \mathrm{HbA1c}-0.112$; that means when HbAlc increased by $1 \%$, GA increased by $2.87 \%$.

Based on the above correlation of $\mathrm{HbAlc}$ with MBG and with GA, we determined the levels of MBG and GA in the present case. Here, the patient was a middle-aged woman with a chronic disease course and a clear diagnosis of diabetes mellitus. According to hospital findings, her $\mathrm{HbAlc}$ was $<4 \%$ ( $\mathrm{Hgb}$ and Alb levels were normal), and GA was more than 14.5\%. However, upon considering the relationship between $\mathrm{HbAlc}$ with $\mathrm{MBG}$ and with GA, and using the above formula, the patient's MBG was determined to be $3.26 \mathrm{mmol} / \mathrm{L}$ and GA to be $9.65 \%$. It could be seen that the GA and actual glucose levels did not match the level of $\mathrm{HbA1c}$; hence, we established the diagnosis of low glycosylated hemoglobin in this patient.

When HbA1c does not match the actual blood glucose situation, factors that may interfere with $\mathrm{HbAlc}$ should be firstly considered (1, 7). Methodology-specific interference factors included: (1) Abnormal $\mathrm{HbA1c}$ measurements in hemoglobinopathy patients due to variation in hemoglobin levels and the type of measurement method. (2) Pseudoelevation of HbAlc measurement in patients with nephropathy, which may occur due to the formulation of hemoglobin. (3) HbA1c levels detected by ion-exchange chromatography, which can be affected by the charge status of glycosylated and non-glycosylated hemoglobin and can be interfered with by the intermediate (Schiff base) of the HbAlc formation process. All of the above interference factors can be determined by changing the detection methodologies and paying attention to whether any hemoglobin variant is found in the detection process.

In this case, the hemoglobin was detected by ion-exchange chromatography in our hospital, without hemoglobin variant detection in the map and hemoglobin abnormality findings by hemoglobin electrophoresis. The immunoassay was also done and the level of $\mathrm{HbA1c}$ was still detected to be low (3.6\%), which suggested that interference with HbAlc due to detection methodology could be excluded. Other diseases that could cause low HbA1c level include hemolytic diseases, such as erythrocyte membranopathies, immunohemolytic anemia, hemoglobinopathy, and erythrocyte enzymopathy (8), insulinoma, drugs, pregnancy, rapidly progressing type 1 diabetes, severe jaundice, hyperlipidemia, and high doses of vitamins $C$ and vitamins $E$ (9). The patient denied any history of hypoglycemia, anemia, and large doses of vitamin intake. After combining the patient's family history of low HbAlc with the laboratory examinations of elevated reticulocyte level (7.49\%), elevated indirect bilirubin level, and shortened erythrocyte life span (43 days), we first considered the repeated reduction in $\mathrm{HbAlc}$ to be associated with hereditary hemolytic disease. However, after preliminary examination, the patient ruled out the common cause of hereditary hemolysis. Then we performed genetic sequencing and detected a heterozygous variant in PIEZO1 gene. The mutations of this gene may be associated with dehydration hereditary stomatocytosis (DHS) $(10,11)$, which is also known as hereditary xerocytosis. DHS is a rare congenital hemolytic anemia with prevalence estimates of 1: 50000 (12).
It is usually compensatory (moderate anemia, high reticulocyte count) (13). However, with long-term disease development, high hemolytic complications (biliary stones and iron overload) may occur, leading to its aggravation. The PIEZO1 gene encodes for a large transmembrane PIEZO1 cation channel $(14,15)$. Electrophysiological studies have demonstrated that mutations in the PIEZO1 gene might cause delayed inactivation of ion channels, thereby increasing cation permeability, leading to dehydration of red blood cells in patients with DHS (16). Most DHS-associated PIEZO1 mutations are in the highly conserved $\mathrm{COOH}$-terminal region, such as p.R2456H, p.T2127M, and p.E2496ELE, which have been identified in more than 50\% of DHS cases (17). The specific site of this new variant is c.6017T $>$ A (p.V2006D), which is also in the COOH-terminal region with an extremely low frequency in the population. There is no relevant literature report on the pathogenicity of this variant at present, and the variant could be classified as uncertain clinical significance (VUS) according to the ACMG Standards and Guidelines. In addition, protein function prediction tools such as Sorting Intolerant From Tolerant (SIFT), Mutation Taster, and Polymorphism Phenotyping version 2 (Polyphen-2) indicated that it could be a pathogenic mutation. The score of SIFT is 0, Polyphen2 HumVar score is 0.834 , and the prediction of Mutation Taster is disease-causing. All the evidences indicated the high possibility of the pathogenic genetic mutation and protein changes.

It is believed that hereditary hemolysis is also related to the onset of diabetes mellitus. However, the mechanism is not clear. Current hypotheses regarding the mechanism include insulin resistance resulting from iron overload induced by hemolysis, or autoimmune response to pancreatic beta cells resulting from pancreatic beta-cell apoptosis, and inflammation of parenchymal organs including the pancreas (18-21). The additional causes could be the restriction of adequate insulin secretion due to zinc deficiency from anemia (22). For this patient, the decrease in fasting and post-prandial insulin level was not consistent with typical T2DM, suggesting that there may be a specific relationship between DHS and the onset of diabetes mellitus. Recent studies indicated that PIEZO1 is a mechanically activated ion channel that might mediate pressure-induced pancreatitis and regulate diet-induced systemic insulin resistance $(23,24)$. However, there was no evidence proving the mutation on the PIEZO1 gene could directly affect the onset of diabetes. Russo et al. investigated seventy-four hereditary anemias patients by the targeted-NGS panel and found that the coinheritance of PIEZO1 and SEC23B causative mutations resulted in marked iron overload, with very high ferritin levels $(1938 \mathrm{ng} / \mathrm{mL})$ and increased transferrin saturation (TSAT 88\%) (25). Moreover, Orvain et al. investigated 4 DHS patients and indicated that severe iron overload is frequent in DHS patients despite wellcompensated hemolysis and no or little transfusion requirement (26). Recently, Andolfo I et al. demonstrated that functional characterization of erythroferrone (ERFE)-A260S variant could directly caused hepatic iron overload by impairing the BMPSMAD pathway in the congenital dyserythropoietic anemia type II cases with biallelic mutations of SEC23B gene (27). However, more studies on the molecular mechanisms of the dysregulation 
of iron homeostasis in PIEZO1 gain-of-function mutations were required in the future.

Additionally, when serum glucose was not consistent with HbA1c, GA should be measured simultaneously since it is unaffected in patients with hemolysis (28). There has been a significantly negative correlation between the GA/HbAlc ratio and hemoglobin in patients with hemolysis $(R=-0.710)$, including diabetic patients, so that the GA/HbA1c ratio could reflect the degree of hemolysis in diabetic patients with hemolytic anemia (29).

In the case of abnormally low HbAlc with normal Hgb, we recommend that the methodology for hemoglobin measurement and the diseases that could cause abnormal quantity and quality of red blood cells and hemoglobin be considered. Since hemolysis with normal $\mathrm{Hgb}$ is not uncommon, the clinical significance of reticulocyte level should not be ignored. At the same time, it should be noted that hereditary hemolysis may have the relationship with diabetes mellitus, and therefore, we suggest that attention be given to reducing the burden of the pancreas when oral drugs are used to control serum glucose.

\section{DATA AVAILABILITY STATEMENT}

The original contributions presented in the study are included in the article/supplementary material, further inquiries can be directed to the corresponding author/s.

\section{REFERENCES}

1. American Diabetes A. Standards of medical care in diabetes-2019 abridged for primary care providers. Clin Diabetes. (2019) 37:11-34 doi: $10.2337 / \mathrm{cd} 18-0105$

2. Rohlfing C, Wiedmeyer HM, Little R, Grotz VL, Tennill A, England J, et al. Biological variation of glycohemoglobin. Clin Chem. (2002) 48:1116-8. doi: 10.1093/clinchem/48.7.1116

3. Joob B, Wiwanitkit V. Very low HbA1C, is it a problem? Iran J Pathol. (2018) 13:379-80.

4. Nathan DM, Kuenen J, Borg R, Zheng H, Schoenfeld D, Heine RJ. Translating the A1C assay into estimated average glucose values. Diabetes Care. (2008) 31:1473-8. doi: 10.2337/dc08-0545

5. Ma XJ, Zhou J, Bao YQ, Lu W, Tang JL, Li M, et al. Investigation on translatiing glycated hemoglobin A1c into mean blood glucose in Chinese subjects. Chin J Diabetes Mellitus. (2011) 3:209-14. doi: 10.3760/cma.j.issn.1674-5809.2011.03.005

6. Ma XJ, Bao YQ, Zhou J, Tang JL, Hu C, Wu SH, et al. Defining the relationship between glycated albumin and HbAlc in individuals with a diverse spectrum of glucose metabolism. China J Endocrinol Metab. (2010) 26:452-55. doi: 10.3760/cma.j.issn.1000-6699.2010.06.005

7. Sherwani SI, Khan HA, Ekhzaimy A, Masood A, Sakharkar MK. Significance of $\mathrm{HbA} 1 \mathrm{c}$ test in diagnosis and prognosis of diabetic patients. Biomark Insights. (2016) 11:95-104. doi: 10.4137/BMI.S38440

8. Wang Z, Sun X, Shi J, Zheng YZ, Zhao YP. [Clinical features and laboratory data analysis of decreased glycosylated hemoglobin related to hemolytic disease]. Zhonghua Xue Ye Xue Za Zhi. (2019) 40:137-40. doi: 10.3760/cma.j.issn.0253-2727.2019.02.008

9. Yazdanpanah S, Rabiee M, Tahriri M, Abdolrahim M, Rajab A, Jazayeri HE, et al. Evaluation of glycated albumin (GA) and GA/HbAlc ratio for diagnosis of diabetes and glycemic control: a comprehensive review. Crit Rev Clin Lab Sci. (2017) 54:219-32. doi: 10.1080/10408363.2017.1299684

\section{ETHICS STATEMENT}

The studies involving human participants were reviewed and approved by Peking union meidical college hospital. The patients/participants provided their written informed consent to participate in this study. Written informed consent was obtained from the individual(s) for the publication of any potentially identifiable images or data included in this articles.

\section{AUTHOR CONTRIBUTIONS}

We declare that AS, YL, ML, XY, and XC contributed to the analysis of the results and to the writing of the manuscript. LL, WX, OW, and XX contributed to read, and approved the final, submitted version of the manuscript. All authors contributed to the article and approved the submitted version.

\section{FUNDING}

This work was supported by the Non-profit Central Research Institute Fund of Chinese Academy of Medical Sciences (Nos. 2017PT32020 and 2018PT32001) and CAMS Innovation Fund for Medical Science (CAMS-2017-I2M-1-011) and the National Key Research and Development Program of China (No. 2016YFC0901500).

10. Andolfo I, Alper SL, De Franceschi L, Auriemma C, Russo R, De Falco $\mathrm{L}$, et al. Multiple clinical forms of dehydrated hereditary stomatocytosis arise from mutations in PIEZO1. Blood. (2013) 121:3925-35, S1-12. doi: 10.1182/blood-2013-02-482489

11. Albuisson J, Murthy SE, Bandell M, Coste B, Louis-dit-Picard H, Mathur J, et al. Dehydrated hereditary stomatocytosis linked to gain-of-function mutations in mechanically activated PIEZO1 ion channels. Nat Commun. (2013) 4:1884. doi: 10.1038/ncomms3440

12. Andolfo I, Russo R, Gambale A, Iolascon A. New insights on hereditary erythrocyte membrane defects. Haematologica. (2016) 101:1284-94. doi: 10.3324/haematol.2016.142463

13. Delaunay J. The molecular basis of hereditary red cell membrane disorders. Blood Rev. (2007) 21:1-20. doi: 10.1016/j.blre.2006.03.005

14. Cinar E, Zhou S, DeCourcey J, Wang Y, Waugh RE, Wan J. Piezol regulates mechanotransductive release of ATP from human RBCs. Proc Natl Acad Sci USA. (2015) 112:11783-8. doi: 10.1073/pnas.1507309112

15. Glogowska E, Schneider ER, Maksimova Y, Schulz VP, Lezon-Geyda K, $\mathrm{Wu}$ J, et al. Novel mechanisms of PIEZO1 dysfunction in hereditary xerocytosis. Blood. (2017) 130:1845-56. doi: 10.1182/blood-2017-05-7 86004

16. Caulier A, Jankovsky N, Demont Y, Ouled-Haddou H, Demagny J, Guitton $\mathrm{C}$, et al. PIEZO1 activation delays erythroid differentiation of normal and Hereditary Xerocytosis-derived human progenitors cells. Haematologica. (2019) 105:610-22. doi: 10.3324/haematol.2019.218503

17. Gallagher PG. Disorders of erythrocyte hydration. Blood. (2017) 130:2699708. doi: 10.1182/blood-2017-04-590810

18. Cappellini MD, Cohen A, Porter J, Taher A, Viprakasit V. Guidelines for the Management of Transfusion Dependent Thalassaemia (TDT). Nicosia: Thalassaemia International Federation (2014).

19. Noetzli LJ, Mittelman SD, Watanabe RM, Coates TD, Wood JC. Pancreatic iron and glucose dysregulation in thalassemia major. Am J Hematol. (2012) 87:155-60. doi: 10.1002/ajh.22223 
20. Walter PB, Fung EB, Killilea DW, Jiang Q, Hudes M, Madden J, et al. Oxidative stress and inflammation in iron-overloaded patients with betathalassaemia or sickle cell disease. Br J Haematol. (2006) 135:254-63. doi: 10.1111/j.1365-2141.2006.06277.x

21. Monge L, Pinach S, Caramellino L, Bertero MT, Dall'Omo A, Carta Q. The possible role of autoimmunity in the pathogenesis of diabetes in B-thalassemia major. Diabetes Metabolism. (2001) 27(2 Pt 1):149-54.

22. Fung EB, Gildengorin G, Talwar S, Hagar L, Lal A. Zinc status affects glucose homeostasis and insulin secretion in patients with thalassemia. Nutrients. (2015) 7:4296-307. doi: 10.3390/nu7064296

23. Zhao C, Sun Q, Tang L, Cao Y, Nourse JL, Pathak MM, et al. mechanosensitive ion channel piezol regulates diet-induced adipose inflammation and systemic insulin resistance. Front Endocrinol. (2019) 10:373. doi: 10.3389/fendo.2019.00373

24. Romac JM, Shahid RA, Swain SM, Vigna SR, Liddle RA. Piezol is a mechanically activated ion channel and mediates pressure induced pancreatitis. Nat Commun. (2018) 9:1715. doi: 10.1038/s41467-018-04194-9

25. Russo R, Andolfo I, Manna F, Gambale A, Marra R, Rosato BE, et al. Multigene panel testing improves diagnosis and management of patients with hereditary anemias. Am J Hematol. (2018) 93:672-82. doi: 10.1002/ajh.25058

26. Orvain C, Da Costa L, Van Wijk R, Pissard S, Picard V, Mansour-Hendili L, et al. Inherited or acquired modifiers of iron status may dramatically affect the phenotype in dehydrated hereditary stomatocytosis. Eur J Haematol. (2018) 101:566-9. doi: 10.1111/ejh.13135
27. Andolfo I, Rosato BE, Marra R, De Rosa G, Manna F, Gambale A, et al. The BMP-SMAD pathway mediates the impaired hepatic iron metabolism associated with the ERFE-A260S variant. Am J Hematol. (2019) 94:1227-35. doi: 10.1002/ajh.25613

28. Kiniwa N, Okumiya T, Tokuhiro S, Matsumura Y, Matsui H, Koga M. Hemolysis causes a decrease in HbAlc level but not in glycated albumin or 1,5-anhydroglucitol level. Scand J Clin Lab Invest. (2019) 79:377-80. doi: 10.1080/00365513.2019.1627577

29. Koga M, Hashimoto K, Murai J, Saito H, Mukai M, Ikegame K, et al. Usefulness of glycated albumin as an indicator of glycemic control status in patients with hemolytic anemia. Clin Chim Acta. (2011) 412:253-7. doi: 10.1016/j.cca.2010.10.014

Conflict of Interest: The authors declare that the research was conducted in the absence of any commercial or financial relationships that could be construed as a potential conflict of interest.

Copyright (C) 2020 Song, Lu, Li, Lin, Yuan, Cheng, Xia, Wang and Xing. This is an open-access article distributed under the terms of the Creative Commons Attribution License (CC BY). The use, distribution or reproduction in other forums is permitted, provided the original author(s) and the copyright owner(s) are credited and that the original publication in this journal is cited, in accordance with accepted academic practice. No use, distribution or reproduction is permitted which does not comply with these terms. 